\title{
EphrinB3 blocks EphB3 dependence receptor functions to prevent cell death following traumatic brain injury
}

\author{
MH Theus ${ }^{1}$, J Ricard ${ }^{2}$, SJ Glass ${ }^{2}$, LG Travieso ${ }^{2}$ and DJ Liebl ${ }^{*, 2}$
}

Eph receptor tyrosine kinases and their membrane-bound ligands, ephrins, have a variety of roles in the developing and adult central nervous system that require direct cell-cell interactions; including regulating axon path finding, cell proliferation, migration and synaptic plasticity. Recently, we identified a novel pro-survival role for ephrins in the adult subventricular zone, where ephrinB3 blocks Eph-mediated cell death during adult neurogenesis. Here, we examined whether EphB3 mediates cell death in the adult forebrain following traumatic brain injury and whether ephrinB3 infusion could limit this effect. We show that EphB3 co-labels with microtubule-associated protein 2-positive neurons in the adult cortex and is closely associated with ephrinB3 ligand, which is reduced following controlled cortical impact (CCl) injury. In the complete absence of EphB3 (EphB3 ${ }^{-1-}$ ), we observed reduced terminal deoxynucleotidyl transferase-dUTP nick end labeling (TUNEL), and functional improvements in motor deficits after $\mathrm{CCl}$ injury as compared with wild-type and ephrinB3 ${ }^{-1-}$ mice. We also demonstrated that EphB3 exhibits dependence receptor characteristics as it is cleaved by caspases and induces cell death, which is not observed in the presence of ephrinB3. Following trauma, infusion of pre-clustered ephrinB3-Fc molecules (eB3-Fc) into the contralateral ventricle reduced cortical infarct volume and TUNEL staining in the cortex, dentate gyrus and CA3 hippocampus of wild-type and ephrinB3 ${ }^{-I-}$ mice, but not EphB3 ${ }^{-1-}$ mice. Similarly, application of eB3-Fc improved motor functions after $\mathrm{CCl}$ injury. We conclude that EphB3 mediates cell death in the adult cortex through a novel dependence receptor-mediated cell death mechanism in the injured adult cortex and is attenuated following ephrinB3 stimulation.

Cell Death and Disease (2014) 5, e1207; doi:10.1038/cddis.2014.165; published online 8 May 2014

Subject Category: Neuroscience

Traumatic brain injury (TBI) is a multifaceted condition initiated by mechanical tissue disruption and induction of a secondary phase of injury that triggers both necrotic- and apoptotic-related events leading to neuronal loss, axonal destruction and demyelination. ${ }^{1-6}$ These events are accompanied by long-term cognitive and neurological deficits in humans ${ }^{7}$ as well as in rodent models of experimental brain injury. ${ }^{8-10}$ A number of studies have demonstrated that TBIinduced neuronal damage is a critical component of the secondary injury, and apoptotic mechanisms account for the majority of cell death. ${ }^{11-14}$ Neuroprotective strategies aimed at preventing apoptosis, cellular damage and the neuropathological sequelae of $\mathrm{TBI}$ have largely failed to translate to clinical treatment. Thus, additional understanding of the molecular mechanisms that regulate apoptotic-mediated neuronal loss following central nervous system (CNS) trauma is warranted.

Ephrins and Eph receptors have traditionally been shown to have important roles in the development of the CNS. ${ }^{15-18}$ Although we know a great deal about their influence in development, a growing number of studies support their role in the injured adult CNS. ${ }^{19,20}$ In particular, temporal expression differences are observed on neurons and glial cells following injury, ${ }^{21-25}$ which in turn function to mediate injury-induced axon sprouting, cellular remodeling and glial scar formation. ${ }^{21,22,26-28}$ Recently, we described a novel 'dependence receptor' function for EphA4 receptors, where these receptors initiate cellular apoptosis in the absence of their ligand(s). ${ }^{29}$ In another study, EphB3 displayed effects that strongly supported its affiliation to the dependence receptors family. ${ }^{30}$ Dependence receptors form a family of receptors that can transduce both positive and negative signals depending on ligand interaction. During normal tissue homeostasis, dependence receptors interact with their cognate ligand to transduce positive cellular changes, such as survival, differentiation and/ or migration; however, in conditions where ligand-receptor interactions are reduced, these receptors initiate or amplify programmed cell death. Therefore, dependence receptors create a cellular state of dependence for their ligand. Activation or elimination of this unique phenomenon is thought to have a key role in embryonic development, neurodegenerative diseases and cancer progression. To date, dependent

\footnotetext{
${ }^{1}$ Department of Biomedical Sciences and Pathobiology, Virginia-Maryland Regional College of Veterinary Medicine, 215 Duck Pond Drive, Blacksburg, VA 24061, USA and ${ }^{2}$ Miami Project to Cure Paralysis, Department of Neurological Surgery, University of Miami Miller School of Medicine, 1095 NW 14th Terrace, R-48, Miami, FL 33136, USA *Corresponding author: DJ Liebl, Miami Project to Cure Paralysis, Department of Neurological Surgery, University of Miami Miller School of Medicine, 1095 NW 14 th Terrace, R-48, Miami, FL 33136, USA. Tel: +1 305243 7143; Fax: +1 305243 3914; E-mail: dliebl@ med.miami.edu

Keywords: ephrins; Eph receptors; controlled cortical impact (CCI) injury; traumatic brain injury (TBI)

Abbreviations: $\mathrm{CCl}$, controlled cortical impact; TUNEL, terminal deoxynucleotidyl transferase-dUTP nick end labeling; eB3-Fc, ephrinB3-Fc molecule; CC, corpus callosum; HEK, human embryonic kidney; CNS, central nervous system; TBI, traumatic brain injury

Received 15.10.13; revised 28.2.14; accepted 17.3.14; Edited by A Verkhratsky
} 
receptor mechanisms have not been appreciated or adequately examined in the context of CNS injury.

Here, we demonstrate that EphB3 mediates cell death in the acute phase of controlled cortical impact $(\mathrm{CCl})$ injury, a murine model of TBI. In the absence of EphB3, we observed increased cell survival and improvements in motor recovery as compared with deficiencies in ephrinB3 or wild-type mice. This supports the unique role of Eph-mediated cell death, where loss of the receptor, but not of the ligand, is protective. Furthermore, like EphA4 and many other dependence receptors, EphB3 undergoes cleavage by caspase(s) to initiate cell death mechanism. Stimulation studies using soluble clustered ephrinB3-Fc (eB3-Fc) support this role, where stimulating Eph signaling reverses $\mathrm{CCl}$ injury-induced phenotypes. These findings provide evidence for a dependence receptor function of EphB3 in the adult brain following trauma, and represent a unique target for neuroprotective strategies.

\section{Results}

EphB3 and ephrinB3 expression in the adult murine cortex and hippocampus. To evaluate the role of EphB3ephrinB3 signaling following $\mathrm{CCl}$ injury, we first determined their cellular localization in the adult cortex and hippocampus, as these areas are selectively damaged following moderate cortical injury. Using immunofluorescence labeling and confocal image analysis, we found that EphB3 was expressed by microtubule-associated protein 2-positive neurons in the cortex (Figures $1 ; 1 \mathrm{a}-\mathrm{c}$ ) and in the CA3 region of the adult hippocampus (Figures $1 ; 2 \mathrm{a}-\mathrm{c}$ ). We also found EphB3 expression throughout the dentate gyrus layers (yellow arrowheads) and on GFAP-positive cells (Figures 1; $3 a-c)$. To examine ephrinB3 expression, we took advantage of a transgenic knock-in mouse where $\beta$-galactosidase (ephrinB3- $\beta$-gal) replaces the cytoplasmic domain of ephrinB3 allowing for selective labeling. Dense $\beta$-galactosidase expression (through $\mathrm{X}$-gal staining) was observed throughout the brain, including the striatum, septum and corpus callosum (CC; Figure 2), and weaker staining within the cortical layers overlying the CC (Figures 2; $1 \mathrm{a}-\mathrm{c})$ as well as in the dentate gyrus pyramidal layers (Figures 2; 3a-c); however, in the cortex and CA3 hippocampus, staining was seen adjacent to NeuN-positive neuron cell bodies rather than within them (Figures $2 ; 2 a-c)$. $\beta$-Galactosidase expression was observed in regions that correlate with axon and dendritic growth in the dentate granule cells and CA1 pyramidal neurons, which supports our previous studies where ephrinB3 mRNA expression was observed in the DGC and CA1 cell layers ${ }^{16,18}$ and synaptic membranes. ${ }^{18}$ Together, these studies support a similar regional expression pattern between ephrinB3 and EphB3 in neurons that reside in both the cortex and hippocampus.

Histological assessment using Nissl staining on brain sections from $\mathrm{CCl}$-injured mice showed cellular loss in the cortex 3 days after injury (Figures $3 a$ and $b$ ). Coincident with neuronal cell loss, ephrinB3 expression visualized by $\mathrm{X}$-gal staining was reduced in the cortex and CC at 3 days after $\mathrm{CCl}$ injury (Figures $3 \mathrm{c}$ and d). Western blot analysis showed a significant difference in the levels of ephrinB3 and EphB3 in the cortex at 3 and 7 days post $\mathrm{CCl}$ injury (Figures $3 e-h$ ). In particular, both ephrinB3 and EphB3 levels were reduced in the cortex at 3 days post $\mathrm{CCl}$ injury, whereas only ephrinB3 remained attenuated at 7 days. In whole hippocampal tissues, there was no significant change in the levels of EphB3 at 3 and 7 days post $\mathrm{CCl}$ injury. However, ephrinB3 was significantly reduced by $42 \%$ at 3 days and restored to sham levels by 7 days post injury (not shown). Together, these findings demonstrate that $\mathrm{CCl}$ injury leads to an acute attenuation in ephrinB3 and EphB3 expression, which could result from cell loss and/or reduced protein levels.
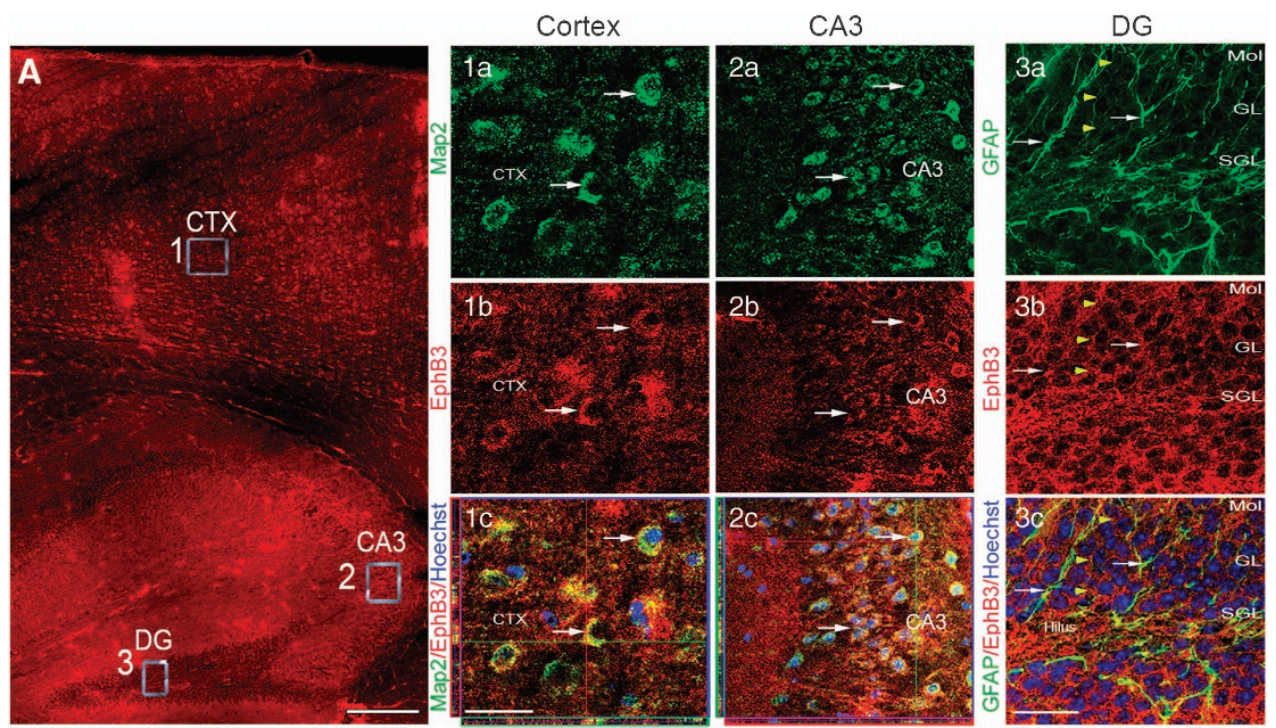

Figure 1 EphB3 expression in the adult murine forebrain. EphB3 $(\mathbf{A})$ is expressed by MAP-2-positive cells in the naive adult cortex (inset 1; 1a-c) and CA3 regions (inset 2; 2a-c) as well as throughout multiple layers of the dentate gyrus (inset 3; $3 a-c)$. EphB3 is expressed by GFAP-positive cells in the DG (3a-c). Scale bar $=500 \mu m$ in image $\mathrm{A} ; 20 \mu \mathrm{m}$ in $\mathrm{E}-\mathrm{H} ; 50 \mu \mathrm{m}$ in $\mathrm{I}-\mathrm{L}$ 


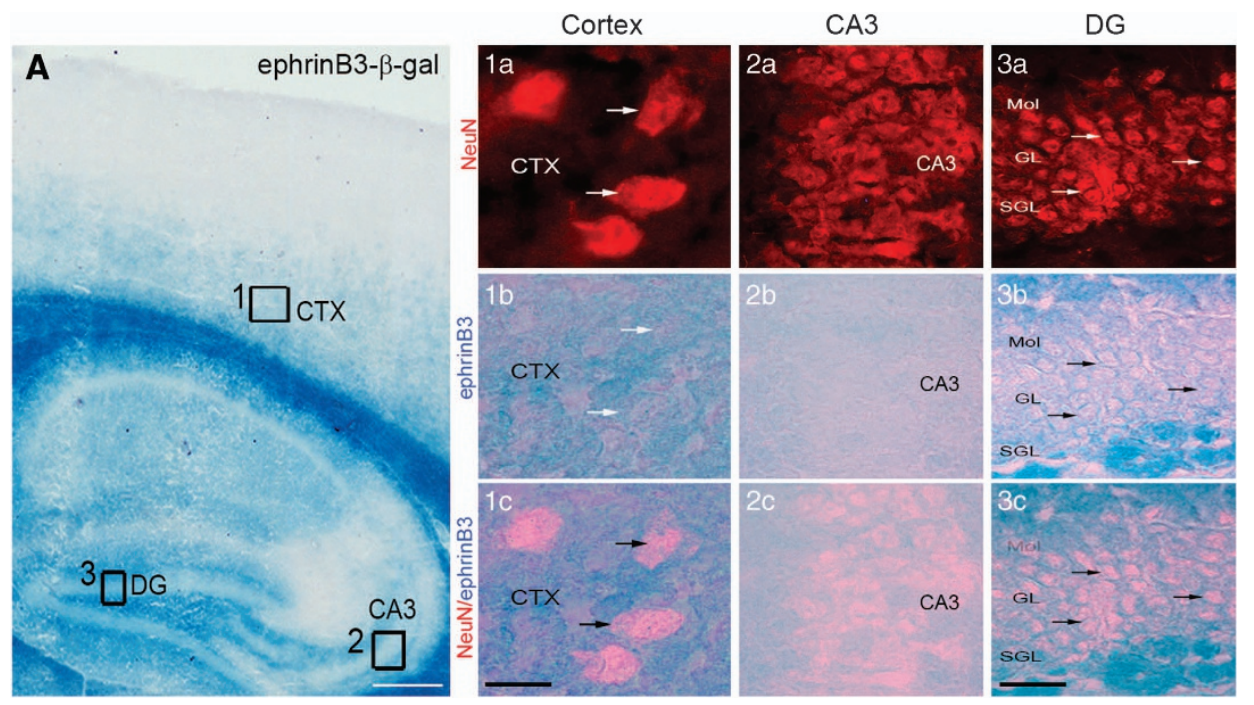

Figure 2 EphrinB3 expression in the adult murine forebrain. Low magnification of a sagittal brain section from ephrinB3 ${ }^{\text {lacZ }}$ mouse (A). EphrinB3 (X-gal staining) is present in the corpus callosum (CC), CA3 and cortical layers IV-VI (CTX). In the cortex (inset 1), CA3 (inset 2) and dentate gyrus (inset 3) NeuN-positive cells (1a; 2a; 3a) are adjacent to ephrinB3 staining ( $1 \mathrm{~b}$ and $\mathrm{c} ; 2 \mathrm{~b}$ and c). (1a-3a) NeuN-positive neurons magnified from image A, within the cortex (1a), CA3 (2a) and dentate gyrus (3a). Scale bar $=500 \mu \mathrm{m}$ in image $\mathrm{A} ; 20 \mu \mathrm{m}$ in $1 \mathrm{a}-1 \mathrm{c} ; 50 \mu \mathrm{m}$ in $2 \mathrm{a}-3 \mathrm{c}$

Cell death and motor deficits are attenuated in EphB3 ${ }^{-} I^{-}$ mice following $\mathbf{C C l}$ injury. To examine whether ephrinB3EphB3 signaling has a role in CNS damage after $\mathrm{CCl}$ injury, cell death was analyzed by counting the number of terminal deoxynucleotidyl transferase-dUTP nick end labeling (TUNEL)-positive cells in the cortex, dentate gyrus and CA3 hippocampal regions of wild-type, ephrinB3 ${ }^{-1}$ and EphB3 ${ }^{-1-}$ mice at 3 days following $\mathrm{CCl}$ injury. EphrinB3 ${ }^{-1-}$ nor EphB3 ${ }^{-1-}$ mice show no signs of phenotypic abnormalities in cortical cell numbers or cortical development. Shaminjured animals did not display any TUNEL labeling in the cortex; however, there was significant labeling in the injured cortex of wild-type animals (333200 \pm 35130 cells, $n=6)$, which was similar to that of ephrinB3 ${ }^{-1-}$ mice (330200 \pm 63070 cells, $n=5$; Figure 4a). Interestingly, there was a significant decrease in the number of TUNEL-positive cells in $\mathrm{EphB3}^{-1-}$ mice $(190500 \pm 44280$ cells, $n=5)$ compared with wild type at 3 days following $\mathrm{CCl}$ injury. We also observed a non-significant decrease in contusion volume in $\mathrm{EphB3}^{-1-}$ compared with wild-type and ephrinB3 ${ }^{-1-}$ mice (Figure 4b). The total number of TUNEL-positive cells was not significantly different in the CA3 (Figure 4c) or dentate gyrus (Figure $4 d$ ) regions of the hippocampus following $\mathrm{CCl}$ injury. To determine whether reduced cell death in the cortex of $\mathrm{EphB3}^{-/-}$mice correlated with functional differences, RotaRod behavioral analysis was performed on wild-type and $\mathrm{EphB3}^{-1-}$ mice at $3,5,7$ and 14 days after sham or $\mathrm{CCl}$ injury. We observed a significant attenuation in motor behavior of all $\mathrm{CCl}$-injured mice at 3 days post injury, but only wild-type $\mathrm{CCl}$-injured mice showed significant reductions from sham mice at days 5 and 7 post $\mathrm{CCl}$ injury (Figure 4e). At 7 days post $\mathrm{CCl}$ injury, EphB3 $^{-1-}$ CCl-injured mice $(93.7 \pm 3.4 \%$ of baseline, $n=7)$ showed significantly better motor behavior scores as compared with $\mathrm{CCl}$-injured wild-type mice $(77.7 \pm 3.5 \%$ of baseline, $n=7)$, suggesting that EphB3 has a deleterious role following TBI that may likely occur through its ability to promote cell death.

EphrinB3 infusion reduces cell death and motor dysfunction following $\mathbf{C C l}$ injury. We had previously shown that in the absence of ephrinB3 or in the presence of overexpressed Eph receptors, induction of cell death occurs. ${ }^{29,30}$ Our current findings support a role for EphB3 as a potential pro-death dependence receptor following TBI. In the $\mathrm{CCl}$-injured cortex, this is supported by reduced expression of ephrinB3 at 3 and 7 days post $\mathrm{CCl}$ injury (Figure 2), which coincides with tissue damage and functional deficits. However, it is unclear whether loss of ephrinB3 alone is sufficient to induce dependence receptor-mediated cell death. To better demonstrate the pro-survival effects of ephrinB3, we infused it directly into the brain in an attempt to block EphB3-mediated cell death. Thus, we infused soluble pre-clustered ephrinB3-Fc (1.7 $\mu \mathrm{g} / \mathrm{day}$; eB3-Fc) molecules into the contralateral ventricles of wild-type, ephrinB3 ${ }^{-/-}$and EphB3 $^{-1-}$ mice for 3 days following $\mathrm{CCl}$ injury. We quantified contusion volume and cell death in the cortex, dentate gyrus and hippocampal CA3. We found that eB3-Fc infusion significantly reduced the number of TUNEL-positive cells in the cortex of wild-type mice (Fc control: $333400 \pm 51530$, $n=5$ versus eB3-Fc: $175200 \pm 17630, n=5)$ and ephrinB3 ${ }^{-1-}$ mice (Fc control: $324800 \pm 38400, n=5$ versus eB3-Fc: $164100 \pm 39220, n=5$; Figure $5 a$ ) at 3 days following $\mathrm{CCl}$ injury. In addition, reduced cell death observed in the cortex following eB3-FC infusion correlated with a decrease in contusion volume in wild-type and ephrinB3 ${ }^{-1-}$ mice (Figure 5b). In the absence of EphB3, reduced cell death was observed in the cortex but stimulation using soluble ephrinB3 ligand had no effect compared with wild-type mice (Figure 5a). A similar profile was observed in the analysis of the contusion volume between wild-type, EphB3 ${ }^{-/}$and ephrinB3 ${ }^{-1-}$ mice (Figure 5b). In the hippocampus, there was a trend toward 

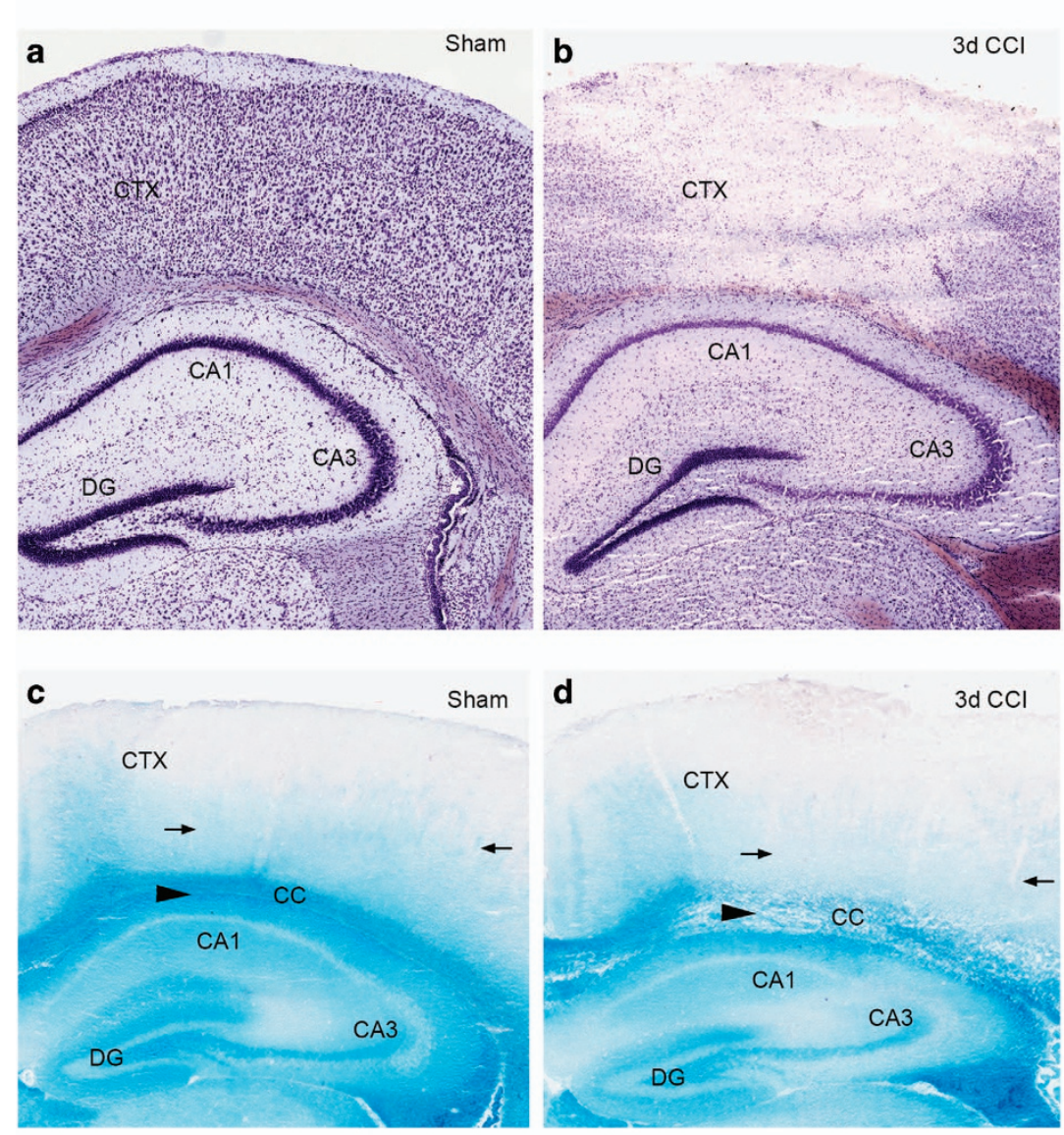


g

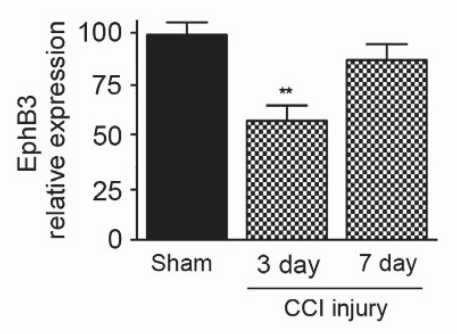

h

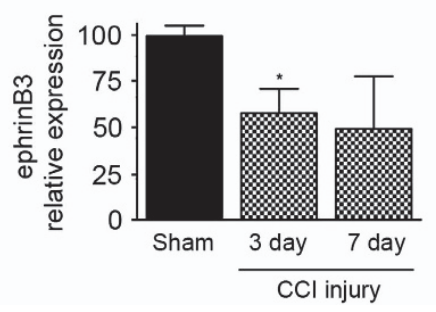

Figure 3 EphB3 and ephrinB3 protein levels are reduced in the cortex post CCl injury. Low-magnification images of Nissl-stained coronal sections at 3 days post sham (a) and $\mathrm{CCl}$ injury (b) showing selective cortical tissue loss with sparing of hippocampal structures. (c and d) X-gal staining in ephrinB3 ${ }^{\text {lacZ }}$ mice after sham and $\mathrm{CCl}$ injury, respectively, demonstrates reduced staining in the cortex (CTX) and corpus callosum (C). (e and f) Western blot analysis for EphB3 and ephrinB3 expression in the cortex at 3 days (e) and 7 days (f) post injury. Significant reductions in EphB3 expression were observed at 3 days, as measured by densitometry normalized to $\beta$-actin control levels ( $\mathbf{g}$ ), whereas ephrinB3 expression was reduced, significantly, at 3 days and non-significantly at 7 days compared with sham-injured levels $(\mathrm{h}) .{ }^{* *} P<0.01 ;{ }^{*} P<0.05$ compared with sham injury. $n=5$ per group and time point

reduced cell death following eB3-Fc infusion in the CA3 hippocampus (Figure 5c) and dentate gyrus (Figure $5 \mathrm{~d}$ ) in wild-type and ephrinB3 ${ }^{-1-}$ mice. Little to no difference was observed in $\mathrm{EphB3}^{-1-}$ mice. Together, these data support EphB3-mediated neuronal and possibly non-neuronal cell death and its potential role in regulating dependence receptor-like activities in the cortex following TBI.

To evaluate whether the pro-survival effects of ephrinB3 could lead to functional improvements, we infused preclustered eB3-Fc or Fc molecules into sham and CCl-injured wild-type mice and assessed motor function using RotaRod behavioral analysis at 3, 7 and 14 days post injury. We found a significant reduction in motor deficits following eB3-Fc infusion $(91.7 \pm 7.7 \%$ of baseline control, $n=12)$ compared with Fc controls ( $68.6 \pm 3.6 \%$ of baseline control, $n=7$ ) at 3 days after $\mathrm{CCl}$ injury (Figure 5e). Furthermore, sham mice infused with eB3-Fc had a similar motor response as sham animals infused with Fc molecules only, demonstrating that this effect is specific to $\mathrm{CCl}$-induced deficits. Overall, these findings demonstrate that restoring ephrinB3 levels in the cortex and maintaining interactions with the EphB3 receptors can reduce cell death and limit motor deficits produced by moderate $\mathrm{CCl}$ injury.

EphrinB3 infusion decreases neuronal cell death in the cortex following $\mathbf{C C l}$ injury. To further evaluate whether ephrinB3 infusion was neuroprotective in the cortex, we analyzed the amount of TUNEL-positive cells that co-labeled with the neuron-specific nuclear protein marker NeuN at 3 days following $\mathrm{CCl}$ injury. Serial coronal sections from $\mathrm{CCl}$ injured mice infused with either Fc molecules (Figure 6a) or eB3-Fc (Figure 6b) were used and stained for TUNEL- and NeuN-positive cells. Visible reductions in TUNEL labeling and infarct volume were observed in the cortex of eB3-Fc infused mice compared with Fc controls. In addition, the total number of cells positive for both TUNEL and NeuN stainings was reduced in the cortex of eB3-Fc-infused mice $(144800 \pm 23270)$ compared with Fc controls (284800 \pm 25870 ; Figure 6c). Furthermore, the percentage of TUNELpositive neurons in the cortex at 3 days post $\mathrm{CCl}$ injury was significantly reduced in wild-type mice that received eB3-Fc infusion $(25.1 \pm 3.6 \%)$ compared with Fc controls $(54.7 \pm 2.7 \%$; Figure $6 \mathrm{~d})$. There were greater numbers of 



Figure 4 Cell death and motor deficits are attenuated in EphB3 ${ }^{-1-}$ mice following $\mathrm{CCl}$ injury. Cell death was quantified in the cortex, CA3 and dentate gyrus 3 days after $\mathrm{CCl}$ injury in wild-type, ephrinB3 ${ }^{-1-}$ and EphB3 ${ }^{-1-}$ mice. (a) The total number of TUNEL-positive cells in the cortex was significantly reduced in EphB3 ${ }^{-1-}$ compared with wild-type and ephrinB3 ${ }^{-1-}$ mice; however, no significant difference in contusion volume was observed between wild-type, ephrinB3 ${ }^{-1-}$ and EphB3 ${ }^{-1-}$ mice (b). In contrast, no significant difference in the number of TUNEL-positive cells was found in the CA3 (c) and dentate gyrus (d) between wild-type, ephrinB3 ${ }^{-1-}$ - and EphB3 ${ }^{-1-}$ -injured mice. (e) Motor deficits following sham and CCl injury using RotaRod assessment at 3, 5, 7 and 14 days post injury in wild-type and EphB3 ${ }^{-1-}$ mice. Compared with pre-training baseline control, wild-type mice had significant motor deficits at 3,5 and 7 days post $\mathrm{CCl}$ injury $(n=7)$ compared with sham-injured $(n=5)$ control mice. Although $\mathrm{CCl}$-injured EphB3 ${ }^{-1-}$ mice $(n=7)$ showed significant motor deficits at 3 days, functional improvement was observed at 5,7 and 14 days compared with sham-injured controls $(n=5)$, with a significant improvement over wild-type injured mice at 7 days. ${ }^{* \star}{ }^{*} P<0.001 ;{ }^{* \star} P<0.01 ;{ }^{*} P<0.05 \mathrm{CCl}$ compared with sham. ${ }^{\#} P<0.05 \mathrm{EphB3}{ }^{-1-} \mathrm{CCl}$ compared with wild-type $\mathrm{CCl}$ injured

NeuN-positive cells in animals infused with eB3-Fc $\left(576800 \pm 20580\right.$ per $\left.\mu \mathrm{m}^{3}\right)$ as compared with Fc controls $(493800 \pm 41130)$ but this difference was not significant (Figure 6e). These data suggest that application of soluble ephrinB3 can substantially limit the extent of neuronal cell death in the cortex at 3 days following $\mathrm{CCl}$ injury.

EphB3 shows dependence receptor attributes. Our in vivo data suggests that EphB3 may function as a dependence receptor to induce cell death in the cortex following TBI. A hallmark of many dependence receptors involves receptor modification through intracellular cleavage by caspase or caspase-like molecules, as previously shown with EphA4. ${ }^{29}$ To further examine the involvement of the EphB3 receptor in mediating caspase-dependent cell death, EphB3 was transiently overexpressed in human embryonic kidney (HEK)-293T cells to evaluate the cleavage response. Using trypan blue to assess cell death, we observed a significant increase in cell death following EphB3 overexpression in HEK293T cells as compared with mock vector controls (Figure 7a), supporting our in vivo observations. Western blot analysis following full-length EphB3 overexpression and serum deprivation revealed a lower migrating band at approximately $20 \mathrm{kDa}$ (Figure $7 \mathrm{~b}$ ). Treatment with a broad range caspase inhibitor, z-VAD-fmk significantly blocked EphB3-induced cell death (Figure 7a) and EphB3 cleavage (Figure 7b), supporting a caspase-dependent mechanism. To further evaluate direct cleavage of the EphB3 intracellular domain by caspases, we modified the aspartic acid residues in regions that would lead to the generation of a $20-k D a$ fragment upon cleavage. Of the eight aspartic acid sites, we mutated (residues 753, 771, 780, 781, 
a
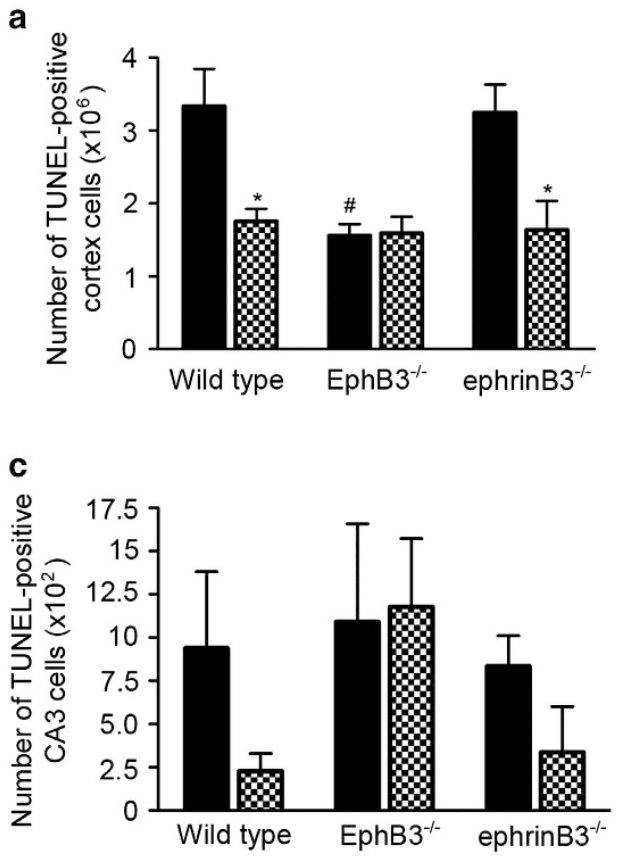


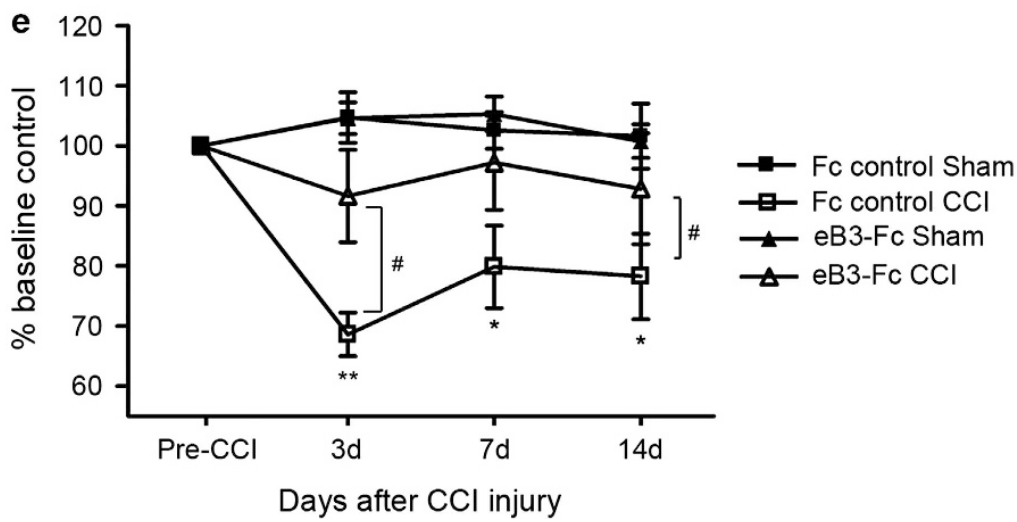

Figure 5 EphrinB3 infusion reduces cell death and motor dysfunction following $\mathrm{CCl}$ injury. Cell death was quantified in the cortex, $\mathrm{CA} 3$ and dentate gyrus 3 days after $\mathrm{CCl}$ injury in wild-type, ephrinB3 ${ }^{-1-}$ and EphB3 ${ }^{-1-}$ mice following infusion of either pre-clustered ephrinB3-Fc (eB3-Fc) or Fc molecules in the contralateral ventricles. (a) Cell death in the cortex was significantly reduced following eB3-Fc infusion in wild-type and ephrinB3 ${ }^{-1}$ mice compared with $\mathrm{Fc}$ control infusions, whereas EphB3 ${ }^{-1-}$ mice showed reduced cell death with both eB3-Fc and Fc controls. (b) A significant reduction in the contusion volume $\left(\mathrm{mm}^{3}\right)$ following eB3-Fc infusion was observed in wild-type and ephrinB3 $^{-1-}$ mice compared with Fc infusions. (c and d) There was non-significant decrease cell death in the CA3 and dentate gyrus following eB3-Fc infusions in wild-type and ephrinB3 ${ }^{-1-}$ mice. (e) Motor deficits using RotaRod analysis in wild-type sham- and CCI-injured mice following infusion with either eB3-Fc or Fc molecules. Although there were significant motor deficits in $\mathrm{CCl}$-injured mice receiving $\mathrm{Fc}$-control, no differences were found in motor function between sham- and CCl-injured mice receiving eB3Fc infusions. (a-d) ${ }^{*} P<0.05$ compared with corresponding Fc-control; ${ }^{\#} P<0.05$ compared with wild-type Fc controls. (e) ${ }^{* *} P<0.01$ compared with Fc control sham-injured mice; ${ }^{\#} P<0.05$ between eB3-Fc infused wild-type and $\mathrm{EphB3}^{-1-}$ mice

$815,836,841,849)$, only the $\mathrm{D}>\mathrm{N}$ mutation at residue 849 decreased cell death (Figure 7a). Similarly, the mutation D849N, but not D841N, prevented caspase-mediated cleavage (Figure 7b). Next, EphB3 and the EphB3 D849N mutant were transiently overexpressed in the human neuroblastoma cell line SY5Y in the presence and absence of eB3-Fc. We observed a significant increase in cell death following EphB3 overexpression in SY5Y cells as compared with mock vector controls (Figure 7c), which could be blocked by stimulating SY5Y cells with eB3-Fc. Similarly, this effect attenuated cell transfection with the D849N mutant with or without eB3-Fc. Together, these findings suggest that EphB3 may mediate neuronal cell death through a novel dependence receptor mechanism, which can be prevented with ephrinB3 treatment following brain trauma.

\section{Discussion}

TBI initiates a complex cascade of events that leads to progressive injury and tissue loss. This study examines a novel mechanism of receptor-mediated cell death following $\mathrm{CCl}$ injury, where EphB3 functions as a pro-cell death dependence receptor. We find that EphB3 is present on MAP-2 expressing neurons, which closely associate with ephrinB3 ligand in the cortex and hippocampus. Astrocytes and oligodendrocytes have been shown to be major sources 

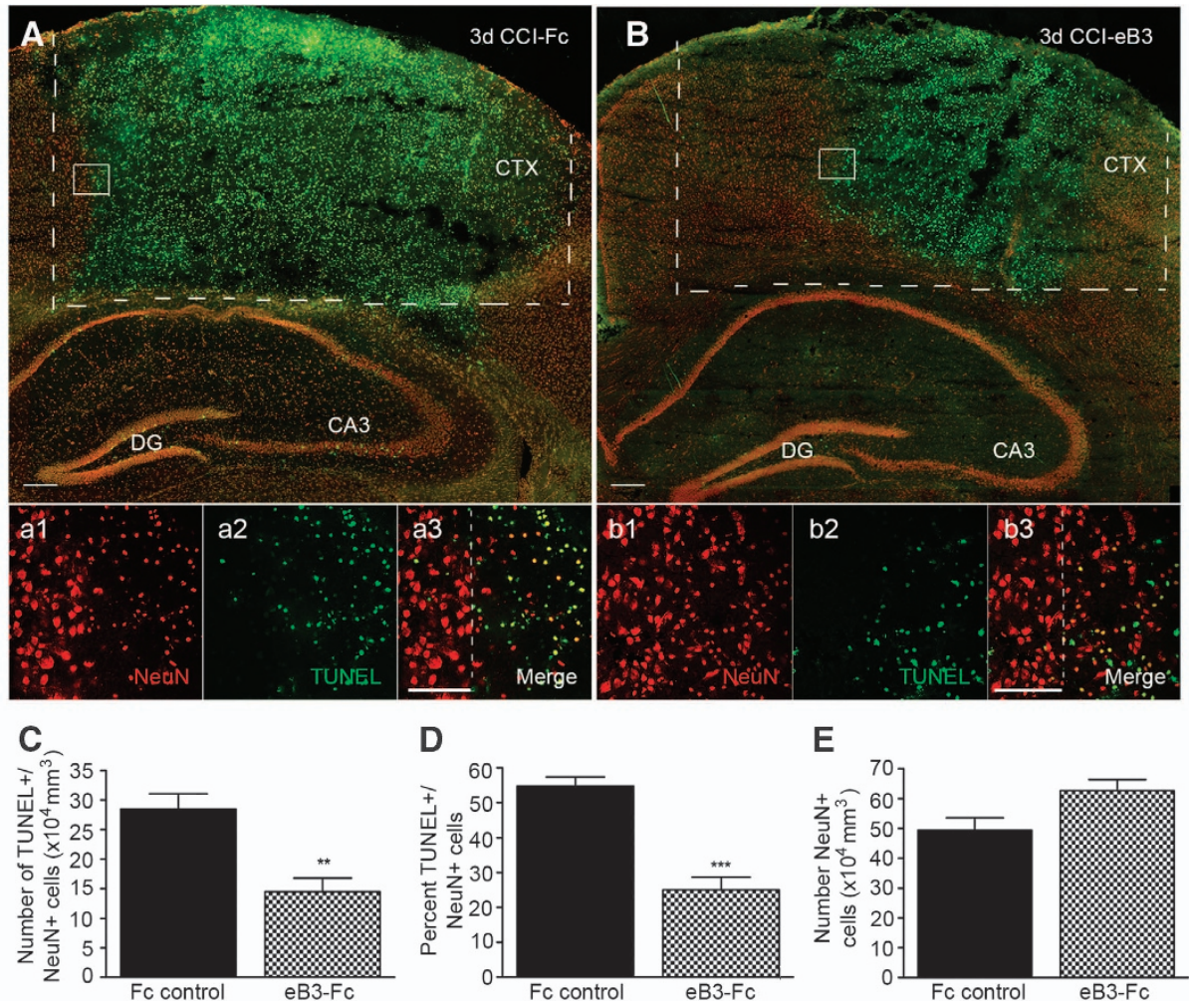

Figure 6 EphrinB3 infusion decreases neuronal tissue loss in the cortex following $\mathrm{CCl}$ injury. (A and $\mathbf{B}$ ) Neuronal cell death was quantified following Fc and eB3-Fc infusion, respectively, by double-labeling for NeuN and TUNEL staining. (A) TUNEL-positive cells (green) were observed throughout the cortex, CA3 and dentate gyrus (DG). (a1-a3) High-magnification images of NeuN staining and TUNEL following 3 days Fc control infusion in wild-type mice. (B) Reduced TUNEL is observed in the cortex following eB3-Fc infusion compared with Fc controls. (b1-b3) High-magnification images of NeuN staining and TUNEL following eB3-Fc infusion. (C-E) Quantified data representing neuronal cell loss in the cortex following Fc control or eB3-Fc infusions. (c) The number of double-labeled TUNEL + /NeuN + cells was significantly reduced in mice receiving eB3-Fc infusions compared with Fc controls. (D) The percentage (\%) of total NeuN + cells that also co-labeled with TUNEL staining was significantly reduced in mice receiving eB3-Fc infusions compared with Fc controls. (E) A non-significant increase in NeuN-positive cells was observed following eB3-Fc infusion compared with Fc control. ${ }^{* \star *} P<0.001$ and ${ }^{* \star} P<0.01$ compared with Fc controls. A and B scale bar $=500 \mu \mathrm{m}$. A3 and B3 scale bar $=100 \mu \mathrm{m}$

of ephrinB3 ligand. $^{31,32}$ Our studies in vitro and in vivo analysis suggest that neuronal-specific EphB3 may induce dependence receptor-mediated cell death following the reduced expression or interaction with ephrinB3 in the adult $\mathrm{CCl}$-injured forebrain that leads to reduced motor performance, a phenotype that is reversed upon administration of ephrinB3-Fc or in the absence of EphB3 (EphB3 ${ }^{-/-}$).

Motor deficits associated with $\mathrm{CCl}$ injury are likely the result of direct damage to motor cortex; however, subcortical regions are also damaged, such as CC and caudate-putamen, which may all contribute to motor dysfunction. Owing to the observation of ephrinB3 expression in deep cortical layers, our results support the possibility of it interacting with EphB3expressing neurons in the motor cortex, although ephrinB3 is also highly expressed in both the CC and caudate-putamen. Finally, it is also possible that other supporting glia expressing EphB3 could contribute to the motor deficits observed following $\mathrm{CCl}$ injury. We do not believe our observations are the result of developmental influences, as motor defects are not observed in adult EphB3 ${ }^{-1-}$ mice nor in sham-injured EphB3 ${ }^{-1-}$ mice. This is further supported by our ability to reverse $\mathrm{CCl}$-induced motor deficits following ephrinB3-Fc infusion. Like other dependence receptors, EphB3 acts as a caspase substrate and undergoes C-terminal cleavage that produces a $20-\mathrm{kDa}$ fragment and ultimately leads to cell death. We cannot rule out that application of saturating amounts of ephrinB3-Fc to block cell death may not only compensate for the downregulation of ephrinB3 in the cortex but also disruption of membrane-bound ephrinB3 interactions with EphB3 in both cortical and subcortical tissues. Alternatively, reduced TUNEL staining and increased neuronal survival in the cortex supports the involvement of EphB3-mediated cell death in the motor cortex. In the future, it will be important to demonstrate Eph receptor cleavage in injured cells early before apoptotic cell loss; however, this has proven difficult to ascertain for several reasons. First, detection of a $\sim 20-\mathrm{kDa}$ EphB3 C-terminal fragment requires a highly specific antibody, which is currently not available and has been difficult to develop. In fact, Eph receptors are highly conserved and generating a site-specific antibody is extremely challenging. Second, receptor cleavage is an early injury event that leads to cell death, so at any given time the populations that contain this cleavage product are eliminated. Thus, in order to address in vivo cleavage within the complex TBI environment, we will need to take a transgenic approach to develop cell-specific transgenic overexpressers with epitope tag and/or transgenic mice containing the D849N 'non-cleavable' mutation. Overall, these studies describe a novel mechanism of cell death following TBI as well as a 




b
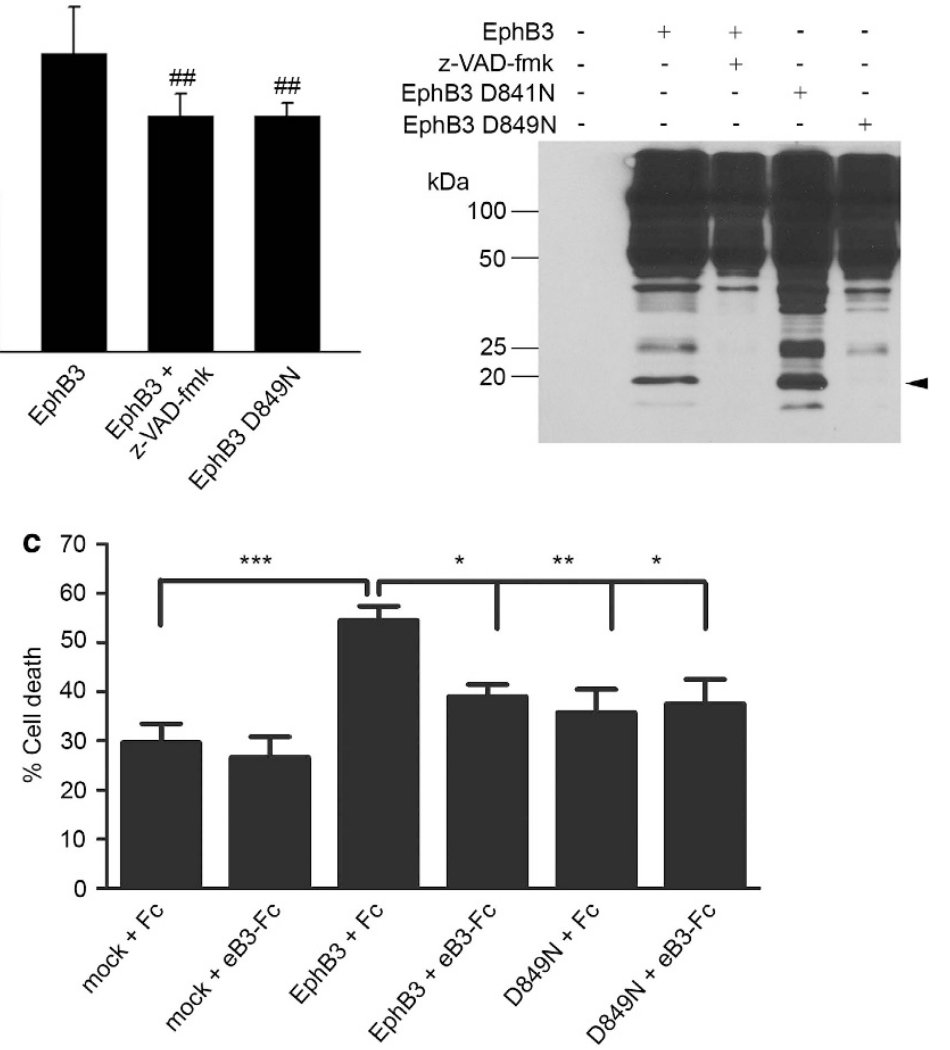

Figure 7 EphB3 overexpression in HEK293T and SY5Y cells leads to increased receptor cleavage and cell death. (a) HEK293T cell cultures overexpressing EphB3 showed greater cell death at $48 \mathrm{~h}$ than cells transfected with a mock vector as measured by Trypan blue exclusion. Addition of the caspase inhibitor, $\mathrm{z}$-VAD-fmk or mutation of the aspartic acid residue in the position 849 to asparagine (D849N) showed a partial but significant reduction in cell death. (b) EphB3 was expressed in HEK293T cells in the absence of serum for $24 \mathrm{~h}$ to trigger cleavage of a $20-\mathrm{kDa}$ fragment shown by western blot analysis. EphB3 cleavage was blocked in the presence of z-VAD-fmk and in EphB3 D849N mutants but not in EphB3 D841N mutants. (c) Cell death is enhanced by EphB3 overexpression in SY5Y cells at $48 \mathrm{~h}$ after transfection, which is blocked by application of $1 \mathrm{mg} / \mathrm{ml}$ eB3-Fc. Overexpression of the D849N mutant does not induce cell death. ${ }^{* * *} P<0.001$ compared with Fc controls and ${ }^{\# \#} P<0.01$ compared with EphB3. ${ }^{\star \star *} P<0.001 ;{ }^{* *} P<0.01 ;{ }^{*} P<0.05$

potential therapeutic strategy to reduce injury onset and progression.

Dependence receptors depend on their ligand to have supportive roles during development or homeostasis, but can convert to a pro-apoptotic receptor in the absence of ligand stimulation. ${ }^{33-37} \mathrm{~A}$ recent report by del Rio and colleagues identified a unique dependence-associated receptor transmembrane motif that is common to many described dependence receptors. ${ }^{38}$ This dependence-associated receptor transmembrane motif is present on both EphB3 and EphA4. Although EphB3 has a high homology with both EphB1 and EphB2, EphA4 is the only other Eph receptor currently shown to function as a dependence receptor. ${ }^{29} \mathrm{EphA}^{29}$ and EphB3 (Figure 7) have a single intracellular cleavage site (residues $773 / 774$ and 849 , respectively) that are critical for caspase cleavage. These two receptors are co-expressed in many cell types, including cortical neurons, ${ }^{31}$ suggesting they may have redundant roles, although this is clearly not the case for many cell functions, as EphB3 and EphA4 knockout mice are not phenotypically similar. This diversity between highly homologous receptors that potentially interact with common ligands may result from higher order receptor complexes, interactions with membrane proteins or unique intracellular signaling intermediates. ${ }^{39}$ Functional diversity may also exist for an individual receptor; for example, EphB3 has been demonstrated to have opposing effects on non-small-cell lung cancer metastasis. Several studies have shown that EphB3 can both promote tumor metastasis ${ }^{40}$ and suppress metastatic progression. ${ }^{41}$ The authors attribute these pro- and anti-apoptotic properties to its ligand interaction and kinase activity, although the mechanisms of action remain poorly defined. It is clear that a better understanding of how Eph interactions regulate cell survival following CNS injury is warranted.

EphB3 has been shown to have a critical role in cell expansion and cell death in adult neurogenesis. ${ }^{30}$ EphB3 limits neural stem/progenitor cell proliferation in the adult subventricular zone thereby maintaining homeostasis of this highly proliferative neurogenic region. ${ }^{29,30}$ Here, we show that EphB3 may also have deleterious roles on residential cells in the adult cortex after traumatic injury. The most convincing evidence that EphB3 functions as a dependence receptor following $\mathrm{CCl}$ injury comes from analysis of the ephrinB3 ${ }^{-1-}$ and EphB3 ${ }^{-1-}$ mice, where deficiencies in the ligandreceptor partners are not phenocopied. However, we would have anticipated increased cell death in the cortex of ephrinB3 $3^{-1}$ mice compared with wild type after $\mathrm{CCl}$ injury 
but the level of damage appeared consistently the same. Previously, we demonstrated the possibility of EphB3 functioning as a dependence receptor by showing opposite effects on cell death between ephrinB3 ${ }^{-1-}$ and $\mathrm{EphB3}^{-1-}$ mice in the naïve SVZ, an area that lies directly adjacent to heavy ephrinB3-expressing regions of the CC and striatum and whose levels of ephrinB3 remain unchanged after $\mathrm{CCl}$ injury. ${ }^{30}$ On the other hand, the cortex expresses much lower levels of ephrinB3, where in layers I-III it is virtually absent. It is possible that downregulation of already low levels of ephrinB3 and dissociation of existing EphB3/ephrinB3 interactions through extensive cellular disruption and tissue loss in the cortex of wild-type mice may mimic an injured ephrinB3 ${ }^{-/-}$ environment and therefore result in a similar outcome. Based on that rationale, we could therefore expect greater differences to occur in the CC between our knockout mice due to higher levels of ephrinB3 expression. Future studies that focus on oligodendrocyte or oligodendrocyte precursor functions in this region may be warranted.

There are a number of membrane receptors that mediate cell death after CNS injury, the most notable being the tumor necrosis factor (TNF) superfamily. ${ }^{42}$ Similar to the Eph family, the TNF receptor superfamily has an extracellular ligandbinding domain, a transmembrane domain and a C-terminal domain containing a death domain that is critical for induction of cell death. Unlike dependence receptors, TNF receptor family members, such as Fas, TNF-receptor 1, TRAIL-R1 and TRAIL-R2 require ligand activation and do not require cleavage of the C-terminal tail to expose the death domain. Thus, TNF receptor-induced cell death results from an active release of TNF, whereas Eph-mediated dependence receptor cell death requires multifunctional responses that include ligand-receptor disruption and receptor modification. Together, these diverse cell death signals contribute to the tissue damage following TBI.

\section{Materials and Methods}

Animals. The generation of the mutant CD1 mice and genotyping using PCR analysis has been previously described. ${ }^{43-46}$ Animals were killed by decapitation under anesthesia; the brain was immediately removed and frozen in Tissue-Tek OCT (Sakura, Torrance, CA, USA) then preserved at $-80^{\circ} \mathrm{C}$ until further processing. Procedures related to animal use and care was approved by the University of Miami Animal Use and Care Committee.

$\mathrm{CCl}$ and infusion. Male mice ages 2-4 months were anesthetized with ketamine and xylazine by i.p. injection and positioned in a stereotaxic frame. Body temperature was monitored with a rectal probe and maintained at $37^{\circ} \mathrm{C}$ with a controlled heating pad set. A $5-\mathrm{mm}$ craniotomy was made using a portable drill over the right parieto-temporal cortex $(-2.0 \mathrm{~mm} \mathrm{~A} / \mathrm{P}$ and $2.0 \mathrm{~mm}$ lateral from bregma). Injury was induced by moderate $\mathrm{CCl}$ using the eCCl-6.3 device (Custom Design and Fabrication, Richmond, VA, USA) at a velocity of $6 \mathrm{~m} / \mathrm{s}$, depth of $0.5 \mathrm{~mm}$ and $150 \mathrm{~ms}$ impact duration. Sham controls received craniotomy only. Following injury, the incision was closed using Vetbond tissue adhesive (3M, St. Paul, MN, USA) and the animals were placed into a heated cage to maintain body temperature for $1 \mathrm{~h}$ post injury. EphrinB3-Fc or control human $\mathrm{Fc}$ molecules (R \& D Systems, Minneapolis, MN, USA) at a concentration of $140 \mu \mathrm{g} / \mathrm{ml}$ were preclustered with goat anti-human $\mathrm{Fc}$ antibodies (ratio 1:5; Jackson Research Laboratories, Inc, West Grove, PA, USA) in phosphate-buffered saline (PBS) for $2 \mathrm{~h}$. Alzet osmotic pumps (Alzet Durect Corp, Cupertino, CA, USA) were preloaded with clustered ephrinB3-Fc or Fc controls, placed in lateral ventricle (from bregma: $\mathrm{A} / \mathrm{P}-0.5 \mathrm{~mm}$; lateral $0.7 \mathrm{~mm}$ ) using stereotactic holder, and secured to cranium with glue. Pumps were placed under the skin of dorsal neck region for an infusion over a 3-day period (12 $\mu \mathrm{l}$ total volume dispensed per day at $0.5 \mu \mathrm{l} / \mathrm{hr}$ rate).
Lesion and hemispheric volumes. Five $30 \mu \mathrm{m}$ sections from bregma levels -1.3 to $-2.2 \mathrm{~mm}, 300 \mu \mathrm{m}$ apart, were stained with cresyl violet for Nissl substance and digitally photographed using an Olympus BX51TRF microscope (Olympus America, Center Valley, PA, USA) with a $\times 4$ objective. The peripheries of the contralateral and ipsilateral hemispheres were traced on each section by an evaluator blinded to the injury and treatment status of each animal, and the cortical lesion volume was calculated using a calibrated image analysis routine, using the software Neurolucida (National Institutes of Health, Bethesda, MD, USA). Lesion volumes were quantified by tracing the contralateral cortex, and projecting the inverted contour over the ipsilateral cortex. The lesion contour was demarcated by pyknotic neurons, hemorrhage and edema. Contusion areas were calculated for five coronal levels at or around the lesion site $(-1.3,-1.6,-1.9,-2.2 \mathrm{~mm}$ posterior from bregma).

Stereology. Fresh frozen coronal, 30- $\mu$ m-thick cryostat brain serial sections were collected from -1.3 to -2.2 bregma (total thickness of the examined tissue was $1500 \mu \mathrm{m})$. Cell death was assessed using TdT-mediated dUTP nickend labeling (TUNEL) staining kit as previously described ${ }^{30}$ with double-labeling for NeuN to identify neurons. The total number of NeuN- and TUNEL-positive cells within $1500 \mu \mathrm{m}$ of cortical tissue were analyzed using a motorized Olympus BX51TRF microscope, Optronix cooled video camera and MicroBrightField Stereolnvestigator software package (MBF Bioscience, Williston, VT, USA). To perform nonbiased cell number estimation, the optical fractionator method and optical dissector probe were used. The cortical lesion, CA3 and dentate gyrus regions were overlaid with contours that covered the entire region of interest using a $\times 10$ magnification stained with Nissl to visualize/identify the anatomical structures in every fifth tissue section $(30 \mu \mathrm{m})$. Next, a grid of $100 \times 100 \mu \mathrm{m}^{2}$ was placed over this area, and the number of TUNEL-, NeuN- and NeuN/TUNEL-positive cells were randomly counted using optical fractionator at $\times 63$ magnification (sampling box: $50 \times 50 \mu \mathrm{m}^{2}$ ).

Staining procedures. For immunostaining, fresh frozen tissue sections were fixed for 5 min with $10 \%$ buffered formalin, washed three times with $1 \times$ PBS, permeabilized for $10 \mathrm{~min}$ in $2: 1$ ethanol/acetic acid solution, washed three times with PBS and permeabilized with $0.4 \%$ Triton X-100 followed by TUNEL labeling. DeadEnd fluorometric TUNEL kit staining was carried out according to the manufacturer's instructions (Promega, Madison, WI, USA). For double labeling with anti-NeuN, the sections were post-fixed with $10 \%$ formalin, subsequently rinsed three times with $1 \times$ PBS and blocked in $5 \%$ BSA $/ 0.2 \%$ Triton in PBS for $1 \mathrm{~h}$, then mouse monoclonal anti-NeuN (1/200 in block, Millipore, Cambridge, UK) was applied overnight at $4{ }^{\circ} \mathrm{C}$. Sections were washed three times with $1 \times$ PBS and AlexaFluor 594-conjugated secondary antibodies (Molecular Probes, Carlsbad, CA, USA) were applied for $1 \mathrm{~h}$ at room temperature. Sections were finally washed with $1 \times$ PBS, counterstained with Hoechst $(0.1 \mu \mathrm{g} / \mathrm{ml}$, Molecular Probes) and mounted in Pro-Long anti-fade mounting solution (Molecular probes). Expression studies used anti-EphB3 (1/200, Abcam, Cambridge, UK), antimicrotubule-associated protein 2 (1/1000, Millipore) and anti-GFAP (1/1000, Dako, Cambridge, UK) antibodies.

RotaRod assessment. Motor function was tested between 3 and 14 days after injury by observers unaware of experimental groups using a RotaRod for mice. The initial velocity was 4 r.p.m. and accelerated to 60 r.p.m. over 10 min. Animals were trained for three consecutive days before $\mathrm{CCl}$ injury with four trials ( 2 min resting in between) each day. Each trial ended when the animal fell off the RotaRod or gripped the rod and passively spun more than once. A baseline was collected on the last day of training. Evaluation of motor function after injury was based on individual scores relative to their baseline latencies.

Cell culture. SY5Y human neuroblastoma cell line, generously donated by Dr. Marion Ehrich VMRCVM, were maintained in L15 media containing 10\% FBS. For transient transfection, 60000 cells were plated per well in a 24-well plate a day before transfection. A complete media change was performed $30 \mathrm{~min}$ before transfection, during which time the plasmids pcDNA3.1-V5, pcDNA3.1-V5-EphB3 and pcDNA3.1-V5-EphB3D849N were mixed with Truefect United Biosystems (Herndon, VA, USA) in DMEM/high glucose (Gibco, Langley, OK, USA) according to manufacturer's recommendation and then $25 \mu \mathrm{l}$ of each complex was added to each respective wells and incubated for $5 \mathrm{~h}$. Media was then removed, washed once with DMEM/high glucose and $500 \mu \mathrm{l}$ of DMEM/high glucose containing either preclusted Fc $(0.5 \mu \mathrm{g} / \mathrm{ml})$ or ephrinB3-Fc $(1.0 \mu \mathrm{g} / \mathrm{ml})$ were added. Forty-eight hours after transfection, trypan blue assay was performed to assess the percentage of cell death for each condition. 
Western blot analysis. Proteins from cortical tissue (carefully dissociated from the CC) were extracted by lysis in RIPA buffer (pH 7.5, $1 \%$ NP- $40,1 \%$ sodium-deoxycholate, $0.1 \% \mathrm{SDS}, 0.15 \mathrm{M} \mathrm{NaCl}, 2 \mathrm{mM}$ EDTA and $0.01 \mathrm{M}$ sodium phosphate) in the presence of Complete protease inhibitor cocktail (Roche, Florence, SC, USA) and phosphatase inhibitor cocktail 2 (Sigma-Aldrich, St. Louis, MO, USA). Supernatant was collected by centrifuging at $14000 \times g$ for $30 \mathrm{~min}$ at $4{ }^{\circ} \mathrm{C}$ and the Lowry assay was used for the determination of protein concentration (Pierce, Rockford, IL, USA). Protein samples were resolved on 10\% SDS-PAGE gels and blotted onto PVDF membranes that were blocked with $5 \%$ BSA or milk in TBST buffer ( $20 \mathrm{mM}$ Tris, $137 \mathrm{mM} \mathrm{NaCl}, 0.1 \%$ Tween) and incubated with primary antibodies against ephrinB3 (1:200, Invitrogen, Carlsbad, CA, USA), EphB3 (1:8000, Abcam), phospho-tyrosine (1:1000, Cell Signaling, Danvers, MA, USA) or $\beta$-actin (1:8000, Cell Signaling) diluted in TBST-3\% BSA or milk overnight at $4{ }^{\circ} \mathrm{C}$. HRP-conjugated secondary antibodies (Jackson Research Laboratories, Inc) in blocking solution were applied to the membrane after four TBST washes and incubated for $2 \mathrm{~h}$ at room temperature. Blots were quantified by densitometry using acquisition into Adobe Photoshop and analyzed by the NIH Image software (National Institutes of Health). The level of protein expression were normalized to $\beta$-actin then represented as percentage of sham-injured control levels for each time point.

Statistical analysis. Data were graphed using GraphPad Prism, version 4 (GraphPad Software, Inc., San Diego, CA, USA). Student's two-tailed t-test was used for comparison of two experimental groups. Multiple comparisons were done using one-way ANOVA followed by Tukey test for multiple pairwise examinations. Changes were identified as significant if $P$ was less than 0.05 . Mean values were reported together with the standard error of mean (S.E.M.)

\section{Conflict of Interest}

The authors declare no conflict of interest.

Acknowledgements. We thank Dr. Mark Henkemeyer for his generous gift of the mutant mice. We also thank Jose Mier for assistance with animal husbandry. This work was supported by the Miami Project to Cure Paralysis, NIH/NINDS NS049545 (DJL), NS30291 (DJL), Department of Defense W81XWH-05-1-0061 (DJL) and NS064699 (MHT).

1. Awasthi D, Church DF, Torbati D, Carey ME, Pryor WA. Oxidative stress following traumatic brain injury in rats. Surg Neurol 1997; 47: 575-581.

2. Chen S, Pickard JD, Harris NG. Time course of cellular pathology after controlled cortical impact injury. Exp Neurol 2003; 182: 87-102.

3. Beer R, Franz G, Srinivasan A, Hayes RL, Pike BR, Newcomb JK et al. Temporal profile and cell subtype distribution of activated caspase-3 following experimental traumatic brain injury. J Neurochem 2000; 75: 1264-1273.

4. Sutton RL, Lescaudron $L$, Stein DG. Unilateral cortical contusion injury in the rat: vascular disruption and temporal development of cortical necrosis. J Neurotrauma 1993; 10: $135-149$.

5. Kumar R, Husain M, Gupta RK, Hasan KM, Haris M, Agarwal AK et al. Serial changes in the white matter diffusion tensor imaging metrics in moderate traumatic brain injury and correlation with neuro-cognitive function. J Neurotrauma 2009; 26: 481-495.

6. Bramlett HM, Dietrich WD. Progressive damage after brain and spinal cord injury: pathomechanisms and treatment strategies. Prog Brain Res 2007; 161: 125-141.

7. Klein M, Houx PJ, Jolles J. Long-term persisting cognitive sequelae of traumatic brain injury and the effect of age. J Nerv Ment Dis 1996; 184: 459-467.

8. Hamm RJ, Dixon CE, Gbadebo DM, Singha AK, Jenkins LW, Lyeth BG et al. Cognitive deficits following traumatic brain injury produced by controlled cortical impact. J Neurotrauma 1992; 9: 11-20.

9. Hamm RJ, Pike BR, O'Dell DM, Lyeth BG, Jenkins LW. The rotarod test: an evaluation of its effectiveness in assessing motor deficits following traumatic brain injury. J Neurotrauma 1994; 11: 187-196.

10. McIntosh TK, Vink R, Noble L, Yamakami I, Fernyak S, Soares $\mathrm{H}$ et al. Traumatic brain injury in the rat: characterization of a lateral fluid-percussion model. Neuroscience 1989; 28: 233-244.

11. Gorio A, Gokmen N, Erbayraktar S, Yilmaz O, Madaschi L, Cichetti C et al. Recombinant human erythropoietin counteracts secondary injury and markedly enhances neurological recovery from experimental spinal cord trauma. Proc Natl Acad Sci USA 2002; 99: 9450-9455.

12. Kang JQ, Chong ZZ, Maiese K. Critical role for Akt1 in the modulation of apoptotic phosphatidylserine exposure and microglial activation. Mol Pharmacol 2003; 64: 557-569.
13. Sakanaka M, Wen TC, Matsuda S, Masuda S, Morishita E, Nagao M et al. In vivo evidence that erythropoietin protects neurons from ischemic damage. Proc Natl Acad Sci USA 1998; 95: 4635-4640.

14. Knoblach SM, Alroy DA, Nikolaeva M, Cernak I, Stoica BA, Faden Al. Caspase inhibitor $z$-DEVD-fmk attenuates calpain and necrotic cell death in vitro and after traumatic brain injury. J Cereb Blood Flow Metab 2004; 24: 1119-1132.

15. Howard MA, Rodenas-Ruano A, Henkemeyer M, Martin GK, Lonsbury-Martin BL, Liebl DJ. Eph receptor deficiencies lead to altered cochlear function. Hear Res 2003; 178 : 118-130.

16. Liebl DJ, Morris CJ, Henkemeyer M, Parada LF. mRNA expression of ephrins and Eph receptor tyrosine kinases in the neonatal and adult mouse central nervous system. J Neurosci Res 2003; 71: 7-22.

17. Mendes SW, Henkemeyer M, Liebl DJ. Multiple Eph receptors and B-class ephrins regulate midline crossing of corpus callosum fibers in the developing mouse forebrain. $J$ Neurosci 2006; 26: 882-892.

18. Rodenas-Ruano A, Perez-Pinzon MA, Green EJ, Henkemeyer M, Liebl DJ. Distinct roles for ephrinB3 in the formation and function of hippocampal synapses. Dev Biol 2006; 292: $34-45$.

19. Goldshmit $Y$, McLenachan S, Turnley A. Roles of Eph receptors and ephrins in the normal and damaged adult CNS. Brain Res Rev 2006; 52: 327-345.

20. Pasquale EB. Eph receptor signalling casts a wide net on cell behaviour. Nat Rev Mol Cell Biol 2005; 6: 462-475.

21. Cruz-Orengo L, Figueroa JD, Velazquez I, Torrado A, Ortiz C, Hernandez C et al. Blocking EphA4 upregulation after spinal cord injury results in enhanced chronic pain. Exp Neurol 2006; 202: 421-433

22. Figueroa JD, Benton RL, Velazquez I, Torrado Al, Ortiz CM, Hernandez CM et al. Inhibition of EphA7 up-regulation after spinal cord injury reduces apoptosis and promotes locomotor recovery. J Neurosci Res 2006; 84: 1438-1451.

23. Miranda JD, White LA, Marcillo AE, Willson CA, Jagid J, Whittemore SR. Induction of Eph B3 after spinal cord injury. Exp Neurol 1999; 156: 218-222.

24. Willson CA, Irizarry-Ramirez M, Gaskins HE, Cruz-Orengo L, Figueroa JD, Whittemore SR et al. Upregulation of EphA receptor expression in the injured adult rat spinal cord. Cell Transplant 2002; 11: 229-239.

25. Willson CA, Miranda JD, Foster RD, Onifer SM, Whittemore SR. Transection of the adult rat spinal cord upregulates EphB3 receptor and ligand expression. Cell Transplant 2003; 12: 279-290.

26. Omoto S, Ueno M, Mochio S, Yamashita T. Corticospinal tract fibers cross the ephrin-B3negative part of the midline of the spinal cord after brain injury. Neurosci Res 2011; 69: 187-195.

27. Goldshmit $Y$, Galea MP, Wise G, Bartlett PF, Turnley AM. Axonal regeneration and lack of astrocytic gliosis in EphA4-deficient mice. J Neurosci 2004; 24: 10064-10073.

28. Sobel RA. Ephrin A receptors and ligands in lesions and normal-appearing white matter in multiple sclerosis. Brain Pathol 2005; 15: 35-45.

29. Furne C, Ricard J, Cabrera JR, Pays L, Bethea JR, Mehlen $P$ et al. EphrinB3 is an anti-apoptotic ligand that inhibits the dependence receptor functions of EphA4 receptors during adult neurogenesis. Biochim Biophys Acta 2009; 1793: 231-238.

30. Theus MH, Ricard J, Bethea JR, Liebl DJ. EphB3 limits the expansion of neural progenitor cells in the subventricular zone by regulating p53 during homeostasis and following traumatic brain injury. Stem Cells 2010; 28: 1231-1242.

31. Zhuang Z, Yang B, Theus MH, Sick JT, Bethea JR, Sick TJ et al. EphrinBs regulate D-serine synthesis and release in astrocytes. J Neurosci 2010; 30: 16015-16024.

32. Duffy P, Wang X, Siegel CS, Tu N, Henkemeyer M, Cafferty WB et al. Myelin-derived ephrinB3 restricts axonal regeneration and recovery after adult CNS injury. Proc Natl Acad Sci USA 2012; 109: 5063-5068.

33. Mehlen P, Bredesen DE. The dependence receptor hypothesis. Apoptosis 2004; 9: 37-49.

34. Mehlen P, Rabizadeh S, Snipas SJ, Assa-Munt N, Salvesen GS, Bredesen DE. The DCC gene product induces apoptosis by a mechanism requiring receptor proteolysis. Nature 1998; 395: 801-804.

35. Mehlen P, Thibert C. Dependence receptors: between life and death. Cell Mol Life Sci 2004; 61: 1854-1866.

36. Tauszig-Delamasure S, Yu LY, Cabrera JR, Bouzas-Rodriguez J, Mermet-Bouvier C, Guix $C$ et al. The TrkC receptor induces apoptosis when the dependence receptor notion meets the neurotrophin paradigm. Proc Natl Acad Sci USA 2007; 104: 13361-13366.

37. Tulasne D, Deheuninck J, Lourenco FC, Lamballe F, Ji Z, Leroy C et al. Proapoptotic function of the MET tyrosine kinase receptor through caspase cleavage. Mol Cell Biol 2004; 24: 10328-10339.

38. del Rio G, Kane DJ, Ball KD, Bredesen DE. A novel motif identified in dependence receptors. PLoS One 2007; 2: e463.

39. Blits-Huizinga CT, Nelersa CM, Malhotra A, Liebl DJ. Ephrins and their receptors: binding versus biology. IUBMB Life 2004; 56: 257-265.

40. Ji XD, Li G, Feng YX, Zhao JS, Li JJ, Sun ZJ et al. EphB3 is overexpressed in non-smallcell lung cancer and promotes tumor metastasis by enhancing cell survival and migration. Cancer Res 2011; 71: 1156-1166.

41. Li G, Ji XD, Gao H, Zhao JS, Xu JF, Sun ZJ et al. EphB3 suppresses non-small-cell lung cancer metastasis via a PP2A/RACK1/Akt signalling complex. Nat Commun 2012; 3: 667.

42. Guicciardi ME, Gores GJ. Life and death by death receptors. FASEB J 2009; 23: 1625-1637. 
43. Cowan CA, Yokoyama N, Bianchi LM, Henkemeyer M, Fritzsch B. EphB2 guides axons at the midline and is necessary for normal vestibular function. Neuron 2000; 26: 417-430.

44. Henkemeyer M, Orioli D, Henderson JT, Saxton TM, Roder J, Pawson T et al. Nuk controls pathfinding of commissural axons in the mammalian central nervous system. Cell 1996; 86 : 35-46.

45. Orioli D, Henkemeyer M, Lemke G, Klein R, Pawson T. Sek4 and Nuk receptors cooperate in guidance of commissural axons and in palate formation. EMBO J 1996; 15 6035-6049.

46. Yokoyama N, Romero Ml, Cowan CA, Galvan P, Helmbacher F, Charnay P et al. Forward signaling mediated by ephrin-B3 prevents contralateral corticospinal axons from recrossing the spinal cord midline. Neuron 2001; 29: 85-97. (c) (i) Cell Death and Disease is an open-access journal published by Nature Publishing Group. This work is licensed under a Creative Commons Attribution 3.0 Unported License. The images or other third party material in this article are included in the article's Creative Commons license, unless indicated otherwise in the credit line; if the material is not included under the Creative Commons license, users will need to obtain permission from the license holder to reproduce the material. To view a copy of this license, visit http://creativecommons.org/licenses/by/3.0/ 